\title{
Estudio bibliométrico: 45 años de literatura biomédica en trasplante de células madre hematopoyéticas
}

\section{A Bibliometric Study: 45 Years of Biomedical Literature in Hematopoietic Stem Cell Transplantation}

\section{Estudo bibliométrico: 45 anos de literatura biomédica em transplante de células-tronco hematopoiéticas}

\author{
Jenifer Vanessa Ríos-Moreno, Est. * \\ Silvia Juliana Bueno-Flórez, Est. * \\ Diana Isabel Conde-Hurtado, Est. * \\ Nick Tarazona, MD. ** \\ Claudia Lucía Sossa-Melo, MD., Esp. ***
}

\begin{abstract}
Resumen
Introducción: La bibliometría mide variables de la literatura científica que se describen de forma cuantitativa por medio de análisis estadístico; con esta herramienta se busca evidenciar el impacto de los trasplantes de células madre hematopoyéticas en la literatura de los últimos 45 años. Objetivo: Descripción de la literatura médica indexada en MEDLINE desde 1970 hasta 2015 sobre trasplantes de células madre hematopoyéticas. Metodología: Se realizó una búsqueda en la base de datos MEDLINE a través de GoPubMed y Fabumed. La estrategia de búsqueda fue: "Hematopoietic Stem Cell Transplantation"[Majr] AND "1970:2015"[dp]. Las variables analizadas fueron el número de publicaciones por año, revistas, países y porcentaje de publicaciones sobre trasplantes de células madre hematopoyéticas. Resultados: Se recuperaron 23,295 referencias sobre trasplantes de células madre
\end{abstract}

hematopoyéticas. Se identificaron 1,844 revistas diferentes, el mayor número de publicaciones se encontró en Bone Marrow Transplantation con 2,443 publicaciones, seguida de Blood con 1,375 y Biology of Bone Marrow Transplantation con 1,319 referencias. Estados Unidos fue el país con mayor número de publicaciones con 7,491 (32.15\%); en Latinoamérica fueron publicados 324 (1.39\%). Los descriptores de la literatura más investigados relacionados con el tema fueron: Trasplante de células madre hematopoyéticas con 23,345 publicaciones, humanos con 22,019 y células madre con 17,564 . Conclusiones: Las publicaciones sobre trasplantes de células madre hematopoyéticas han incrementado de forma progresiva durante los 45 años estudiados. Los países desarrollados son los que han realizado mayor investigación del tema, en contraste con el número de publicaciones en total. [Ríos-Moreno JV, Bueno-Flórez SJ, Conde-Hurtado DI, Tarazona N, Sossa-Melo Claudia Lucía. Estudio bibliométrico: 45 años de literatura biomédica en trasplante de células madre hematopoyéticas. MedUNAB 2017-2018; 20(3): 319-326].

\footnotetext{
* Estudiante de Medicina, semillero de Hematología y Trasplante, Universidad Autónoma de Bucaramanga(UNAB), Floridablanca, Santander, Colombia.

** Médico, Fundación ISA, Medellín, Antioquia, Colombia.

*** Médica, especialista en Medicina Interna y Hematología, Fundación Oftalmológica de Santander y Clínica Carlos Ardila Lülle (FOSCAL), Floridablanca, Santander, Colombia
} 
Palabras clave: Células; Revisión; Trasplante de Células Madre Hematopoyéticas; Trasplante de Médula Ósea; Células Madre; Bibliometría; MEDLINE; Trasplante de Células; Hematología.

\section{Abstract}

Introduction: Bibliometric measures variables from the scientific literature that are described quantitatively by means of statistical analysis; this tool seeks to demonstrate the impact of hematopoietic stem cell transplants in the literature throughout the last 45 years. Objective: To describe the indexed medical literature in MEDLINE from 1970 to 2015 on hematopoietic stem cell transplants. Methodology: A search of the MEDLINE database through GoPubMed and Fabumed was performed. The search strategy was: Hematopoietic Stem Cell Transplantation [Majr] and 1970:2015 [dp]. The variables analyzed were the number of publications per year, journals, countries and percentage of publications on hematopoietic stem cell transplants. Results: 23,295 references were recovered on hematopoietic stem cell transplants. 1,844 different journals were identified, the largest number of publications was found in Bone Marrow Transplantation with 2,443 publications, followed by Blood with 1,375 and Biology of Bone Marrow Transplantation with 1,319 references. The United States was the country with the highest number of publications with 7,491 (32.15\%), in Latin America 324 (1.39\%) were published. The most researched descriptors of literature related to the topic were: Transplantation of hematopoietic stem cells with 23,345 publications, humans with 22,019 and stem cells with 17,564. Conclusions: The publications on hematopoietic stem cell transplants have increased progressively during the 45 years studied. The developed countries are the ones that have done more research on the subject, in contrast to the number of publications in total. [RíosMoreno JV, Bueno-Flórez SJ, Conde-Hurtado DI, Tarazona N, Sossa-Melo Claudia Lucía. A Bibliometric Study: 45 Years of Biomedical Literature in Hematopoietic Stem Cell Transplantation. MedUNAB 2017-2018; 20(3): 319-326].

Key words: Cells; Review; Hematopoietic Stem Cell Transplantation; Bone Marrow Transplantation; Stem Cells Bibliometrics; MEDLINE; Cell Transplantation; Hematology.

\section{Introducción}

La bibliometría mide variables de publicaciones científicas como tamaño, crecimiento y distribución, de manera que se puedan describir de forma cuantitativa mediante análisis estadístico. Estos estudios permiten valorar la actividad científica, impacto de las publicaciones y las fuentes para direccionar nuevas investigaciones $(1,2)$.

El Trasplantes de Células Madre Hematopoyéticas (TCMH) es un procedimiento de cuidado estándar que es curativo en condiciones donde no existen otras opciones terapéuticas, como en leucemias, linfomas, mieloma o fallas medulares (3-6). Además en pacientes con síndrome mielodisplásico de riesgo intermedio o alto es el TCMH el que generalmente resulta en una tasa de supervivencia libre de enfermedad a

\section{Resumo}

Introdução: A bibliometria mede variáveis da literatura científica que são descritas quantitativamente por meio de análise estatística; esta ferramenta procura demonstrar 0 impacto dos transplantes de células estaminais hematopoiéticas na literatura dos últimos 45 anos. Objetivo: Descrição da literatura médica indexada em MEDLINE de 1970 a 2015 em transplantes de células-tronco hematopoiéticas. Metodologia: uma pesquisa do banco de dados MEDLINE foi realizada através do GoPubMed e Fabumed. A estratégia de busca foi: "Transplante de células estaminais hematopoiéticas" [Majr] AND "1970: 2015" [dp] As variáveis analisadas foram o número de publicações por ano, periódicos, países e porcentagem de publicações sobre transplantes de células estaminais hematopoiéticas. Resultados: Foram recuperadas 23,295 referências, em transplantes de células estaminais hematopoiéticas. Identificamos 1,844 periódicos diferentes; o maior número de publicações foi encontrado no Transplante de medula óssea com 2,443 publicações, seguido de sangue com 1,375 e Biologia do transplante de medula óssea com 1,319 referências. Os Estados Unidos foi o país com maior número de publicações com 7,491 (32.15\%); na América Latina, foram publicados 324 (1.39\%). Os textos mais pesquisados da literatura relacionados com o tema foram: Transplante de células-tronco hematopoiéticas com 23,345 publicações, humanos com 22,019 e células-tronco com 17,564 Conclusões: As publicações sobre transplantes de células estaminais hematopoiéticas aumentaram progressivamente durante os 45 anos estudados. Os países desenvolvidos são os que fizeram mais pesquisas sobre o assunto, em contraste com o número de publicações no total. [Ríos-Moreno JV, Bueno-Flórez SJ, Conde-Hurtado DI, Tarazona N, Sossa-Melo Claudia Lucía. Estudo bibliométrico: 45 anos de literatura biomédica em transplante de células-tronco hematopoiéticas. MedUNAB 2017-2018; 20(3): 319-326].

Palavras-chave: Células; Revisão; Transplante de CélulasTronco Hematopoéticas; Transplante de Medula Óssea; Células-Tronco; Bibliometria; MEDLINE; Transplante de Células; Hematologia.

largo plazo de en un 30\% a 50\% (7). En pacientes con leucemia mieloide aguda de riesgo intermedio en primera remisión completa, se ha visto que el trasplante alogénico de células madre hematopoyéticas tiene significativamente mejores tasas de supervivencia libre de enfermedad, mayores tasas de supervivencia global, y menores tasas de recaída comparado con el trasplante autólogo de células madre hematopoyéticas y/o quimioterapia. La principal indicación para autotrasplante fueron las neoplasias linfoproliferativas incluyendo el mieloma múltiple y para los trasplantes alogénicos fueron las leucemias (8).

En un estudio realizado en 12 países latinoamericanos se evidenció que la tasa de TCMH viene en ascenso, con un incremento del $30 \%$ del 2009 al 2012; sin embargo, es 5 a 8 veces más bajo que en regiones Europeas y Norteamericanas, a su vez se evidenció que en el año 2012 
más del 90\% de los TCMH se realizaron principalmente en tres regiones: Norteamérica, Europa y Asia-Pacífico (8).

A nivel nacional, datos del Instituto Nacional de Salud de Colombia muestran que durante el periodo 2010 a 2014 se realizaron 1,814 TCMH, de los cuales 127 fueron haploidénticos, 601 alogénicos y 1,086 autólogos (9). En Santander, datos del único centro de TCMH en la Fundación Oftalmológica de Santander, reportan que desde noviembre de 2009 hasta el 15 de julio de 2015 se han trasplantado 56 pacientes (10). De ellos el más frecuente fue el trasplante autólogo, con 48 trasplantes realizados (85.7\%), su principal indicación fue el mieloma múltiple con 23 trasplantes (48\%), mientras que la del trasplante alogénico fue la leucemia aguda con 6 trasplantes realizados (75\%) (11). Por lo tanto, es importante incrementar la necesidad de realización de investigación sobre TCMH en países subdesarrollados como Colombia. El objetivo de esta revisión es realizar la descripción de la literatura médica indexada en Medline desde 1970 hasta 2015 sobre TCMH.

\section{Metodología}

Análisis bibliométrico descriptivo de corte retrospectivo, que utiliza como fuente de información la base de datos MEDLINE, para analizar las referencias disponibles en los últimos 45 años sobre TCMH. La búsqueda fue realizada en Abril del año 2016 en la base de datos MEDLINE por medio de Fabumed y GoPubMed, los cuales permitieron analizar la información a través de términos $\mathrm{MeSH}$, referentes al TCMH junto a las palabras: Major topic, para ello se seleccionaron los términos "Hematopoietic Stem Cell Transplantation" y el periodo de tiempo analizado: 1970 hasta el 2015, de manera que la estrategia de búsqueda fue: "Hematopoietic Stem Cell Transplantation"[Majr] AND "1970:2015"[dp]; además, se realizó una búsqueda sobre los términos más relacionados con el tema, resaltando el número de publicaciones sobre: hematología, trasplante de células hematopoyéticas y células madre.

Se incluyeron artículos originales, revisiones sistemáticas, metaanálisis, reseñas e informes científicos para abarcar la literatura disponible; teniendo como base la información recolectada se elaboraron gráficas en una hoja de cálculo de Microsoft Office Excel 2011 sobre el número de publicaciones por año entre 1970 y 2015 , se organizaron las publicaciones de acuerdo al país de procedencia, ubicación geográfica, términos con mayor interés dentro de la búsqueda y las tablas sobre revistas con mayor cantidad de artículos publicados sobre TCMH desde 1985 a 2015.

En este análisis se utilizó la herramienta Fabumed, un buscador web que contiene a GoPubMed (12) por medio del cual se realizó la búsqueda de información a través de la base de datos PubMed; un motor de búsqueda gratuito que obtiene la información de la principal base de datos del mundo: la Biblioteca Nacional de Medicina de Estados Unidos que usa el interfaz web (Medline), desarrollado por el National Center for Biotechnology Information (NCBI) (13), que permite usar términos ontológicos para identificar los artículos que se encuentren publicados en las revistas indexadas. Fabumed organiza la información de acuerdo al número de publicaciones científicas, tendencias de las publicaciones, países, ciudades, revistas con mayor número de publicaciones, términos y autores más citados y porcentajes de publicaciones sobre TCMH. Además se analizó el Índice $\mathrm{H}$ de las principales revistas por medio del programa Publish or Perish Version: 4.26.6 (14); el cual evalúa la cantidad de citaciones que obtienen los artículos, esta información se obtuvo de Enero de 2015 a Abril de 2016. También se analizó el Source Normalized Impact Per Publication (SNIP) que mide el impacto promedio de citas de las publicaciones de una revista (15) y finalmente se halló el Journal Citation Report (JCR) (16), del cual se obtuvo el factor de impacto de las principales revistas; información referente al periodo del 2014 al 2015.

\section{Resultados}

Se obtuvo en total 23,295 referencias (Sin incluir el año 2016), en la primera mitad del periodo estudiado (19701992) se hallaron un total de 551 (2.63\%) artículos, mientras que en la segunda mitad(1992-2015) se encontraron 22,744 (97.63\%) (Figura 1). Es de resaltar que en el año 1970 hubo 1 publicación mientras que en el año 2015 aumentaron a 1,416 y se observó un incremento progresivo desde el año 1992 hasta 2002. Sin embargo, en el periodo de 2002 a 2007 disminuyó el número de publicaciones, el cual permaneció constante hasta el año 2,015.

\section{Revistas}

Las referencias fueron publicadas en 1,844 revistas. La lista fue encabezada por la revista Bone Marrow Transplantation con 2,443 (10.50\%) publicaciones, seguida de Blood con $1,375(5.90 \%)$ y Biology of Bone Marrow Transplantation con 1,319 (5.66\%) (Tabla 1). Las 20 revistas que más publicaron incluyeron 11,055 artículos (47.45\%) sobre TCHM.

Las revistas de alto impacto como Lancet, New England Journal of Medicine, Nature o Journal of the American Medical Association, ocuparon los puestos 34, 35, 159 y 110 respectivamente, en relación a la cantidad de artículos publicados. La revista que obtuvo la mayor cantidad de citas, mayor impacto en las citas de sus publicaciones (SNIP) y mayor factor de impacto (JCR) fue la revista Journal of Clinical Oncology seguida por la Revista Blood. Las revistas con mayor número de publicaciones contaron con un mínimo de 300 artículos sobre TCMH, además se muestra el número de referencias en torno al tema, idioma, índice h, SNIP y JCR (Tabla 1). 
1800

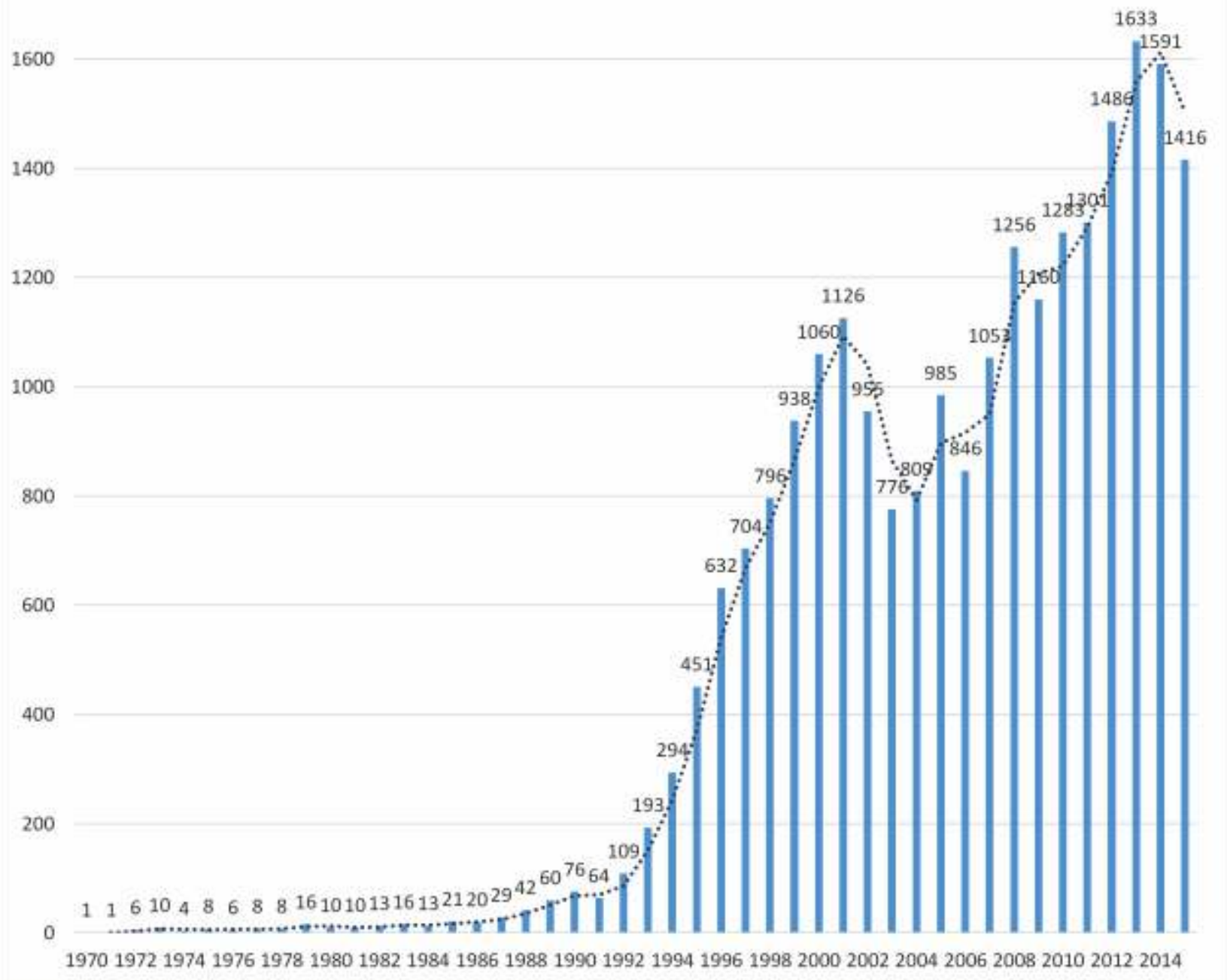

Fuente: Elaboración propia de los autores en Microsoft Excel.

Figura 1. Número de publicaciones por año, de trasplante de células madre hematopoyéticas entre 1970-2015.

\section{Geografía de la investigación}

De los 100 países con publicaciones en el tema, Estados Unidos tuvo el mayor número con 7,491 (32.15\%), seguido de Alemania con 1,666 (7.15\%), Japón con 1,597 (6.85\%), Italia con 1,325 (5.68\%), China con 1,156 (4.96\%) y Francia con 1,155 (4.95\%) (Figura 2). La distribución mundial de las publicaciones se muestra en la Figura 3.

En Latinoamérica se encontraron 324 referencias (1.39\%); encabezado por Brasil con 196 (60.49\%), seguido de México con 64 (19.75\%), Argentina con 28 (8.64\%), Chile con 15 (4.62\%) y Colombia con $10(3.08 \%)$. Este último país en el año 2001 realizó 1 publicación, durante el periodo comprendido entre 2002 y 2012 no publicaron y entre 2013 y 2015 tuvo su mayor producción científica con 9 publicaciones.

\section{Términos}

Los términos o palabras clave con las que se registraron los artículos de mayor interés dentro de la búsqueda fueron: TCMH, registrado en 23,345 publicaciones, humanos en 22,019 y células madre en 17,564 (Figura 4). En relación a los términos, se observó que la palabra hematología se encontró en 139,913 publicaciones, células madre en 295,182 y trasplante de precursores hematopoyéticos en 45,056 lo que representó un $32.20 \%$ respecto a hematología.

\section{Discusión}

En este análisis bibliométrico se evidenció un incremento progresivo en los últimos 45 años en el número de artículos 
Tabla 1. Revistas con mayor cantidad de artículos publicados sobre trasplante de células madre hematopoyéticas desde 1985 a 2015, el número de publicaciones, su índice h, Snip, y el país de publicación.

\begin{tabular}{lcccccc}
\hline \multicolumn{1}{c}{ Revista } & Artículo & Índice $\mathbf{h}^{*}$ & Snip** & País & Idioma & JCR $^{* * *}$ \\
\hline Bone Marrow Transplantation & 2.443 & 19 & 1.38 & Inglaterra & Inglés & 3,636 \\
\hline Blood & 1.375 & 61 & 2.68 & Estados Unidos & Inglés & 11,841 \\
\hline $\begin{array}{l}\text { Biology of Bone Marrow } \\
\begin{array}{l}\text { Transplantation } \\
\text { Bone Marrow Transplantation }\end{array}\end{array}$ & 1.319 & - & - & Estados Unidos & Inglés & 3,980 \\
\hline Haematologica & 1.205 & 19 & 1.38 & Inglaterra & Inglés & - \\
\hline $\begin{array}{l}\text { Journal of Clinical Oncology } \\
\text { British Journal of }\end{array}$ & 426 & 73 & 4.53 & Estados Unidos & Inglés & 20,982 \\
$\begin{array}{l}\text { Haematology } \\
\text { Biology of Blood and Marrow }\end{array}$ & 412 & 27 & 1.60 & Inglaterra & Inglés & 5,812 \\
$\begin{array}{l}\text { Transplantation } \\
\text { Leukemia }\end{array}$ & 432 & 41 & 1.95 & Inglaterra & Inglés & 12,104 \\
\hline $\begin{array}{l}\text { International Journal of } \\
\text { Hematology }\end{array}$ & 301 & 15 & 0.89 & Japón & Inglés & 1,846 \\
\hline
\end{tabular}

Fuente: Elaboración propia de los autores en Microsoft Word.

*Índice h para los años 2014 a 2015, **Snip: source normalized impact per paper, ***JCR: Journal Citation Report.

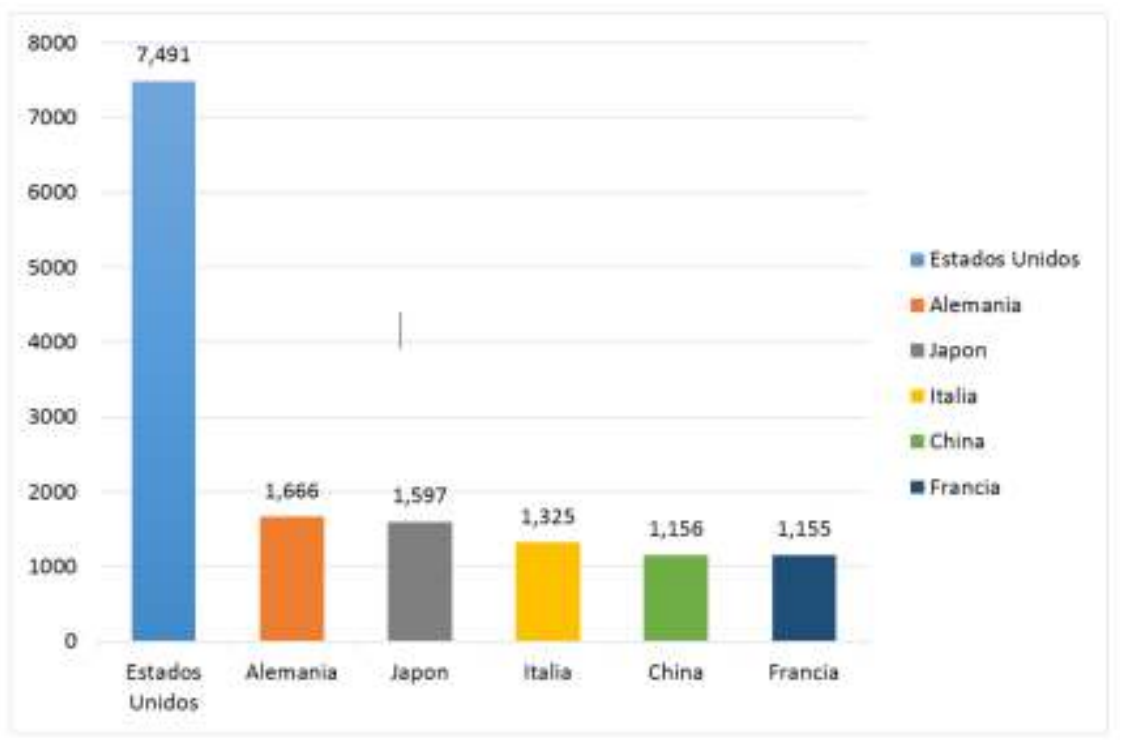

Fuente: Elaboración propia de los autores en Microsoft Excel.

Figura 2. Número de publicaciones de acuerdo al país de procedencia.

publicados sobre TCMH (17). Al igual que en nuestro estudio, un análisis bibliométrico mostró que el crecimiento en la investigación en hematología es mayor en países desarrollados como EEUU, Alemania y Japón (18). Al comparar nuestros resultados con un análisis bibliométrico sobre células pluripotenciales, se observa que en ambas bibliometrías hubo un incremento en el número de artículos publicados después del año 2007 (19).
Un estudio bibliométrico en oncología realizado en 2014, mostró que entre los seis cánceres más frecuentes se encontraban las leucemias (20). En este contexto, el trasplante de células madre hematopoyéticas ha mostrado ser uno de los abordajes terapéuticos más efectivos, dada la mayor tasa de supervivencia y menor número de recaídas comparada con la quimioterapia en estadios avanzados de esta enfermedad(21). 


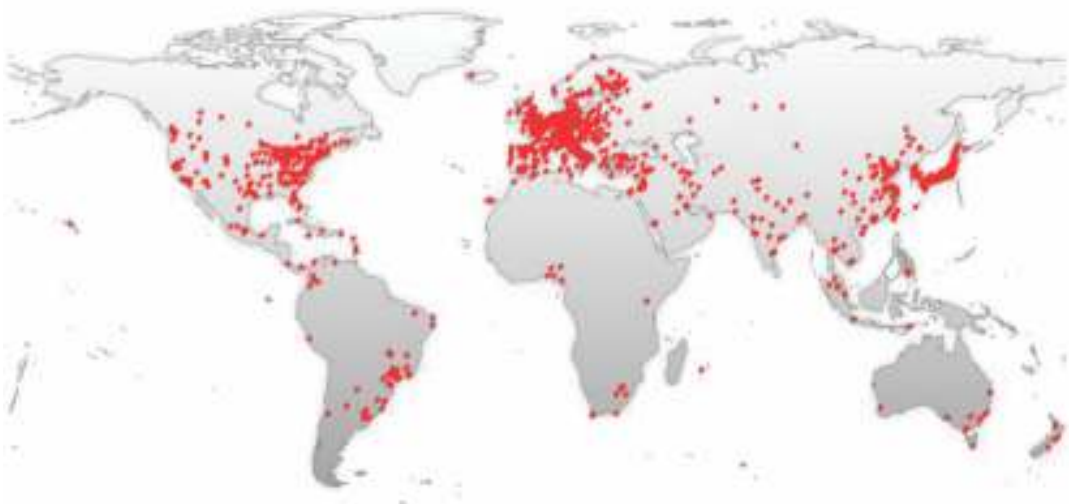

Fuente: Elaboración propia de los autores en Microsoft Word.

Figura 3. Distribución de publicaciones según ubicación geográfica.

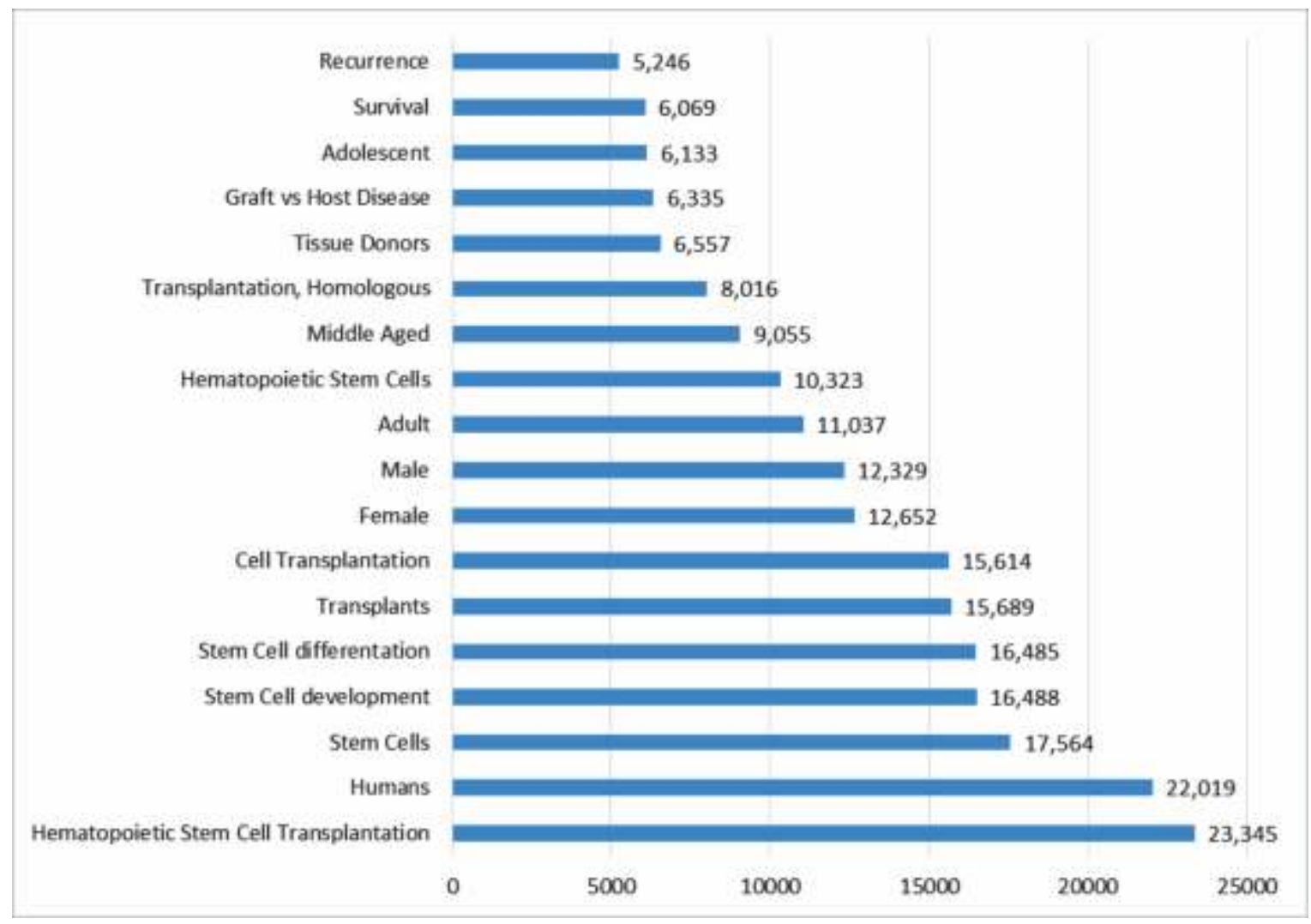

Fuente: Elaboración propia de los autores en Microsoft Word.

Figura 4. Términos con mayor interés dentro de la búsqueda.

Las 10 principales revistas encontradas corresponden al área de hematología, 3 de ellas son de trasplante de médula ósea y las revistas que tienen el mayor factor de impacto medido con el índice H y SNIP son: Journal of Clinical Oncology y Blood, las cuales realizan investigación en diversos campos de la hematología y oncología, evidenciando el interés multidisciplinario en esta especialidad. La revista con mayor número de publicaciones, en torno al tema de TCMH fue Bone Marrow Transplantation, dedicada exclusivamente al trasplante de células hematopoyéticas. No se encontraron revistas que realizarán publicaciones en un idioma diferente al inglés.

Actualmente las guías de manejo (22-24) y metaanálisis, representan un mínimo porcentaje de todas las publicaciones recuperadas sobre TCMH. Debido a que esta terapia es eficaz en el manejo de diferentes patologías de origen hematológico, se esperaría que hubiese más metaanálisis y revisiones 
sistemáticas, además al realizar una búsqueda de análisis bibliométricos sobre TCHM, no se obtuvieron resultados.

EEUU es el país con mayor número de publicaciones, seguido de Alemania y Japón. Por el contrario, Latinoamérica tuvo un mínimo porcentaje de $1.39 \%$ en esta revisión, hay hallazgos que coinciden con estos resultados, ya que en otro análisis bibliométrico se observó que Latinoamérica ha generado el $4.80 \%$ de aportes en temas como cáncer y hematología en la última década. Cabe resaltar que Brasil seguido de México, continúan siendo los países con mayor número de publicaciones en ambos temas, por lo tanto, se considera necesario realizar mayor investigación y divulgación en otros países de esta región (25).

La producción científica en Colombia se incrementó desde el año 2001 hasta el 2015, en este último año se realizó el mayor número de publicaciones, mostrando el creciente interés por este campo; no obstante, aún es bajo el volumen de publicaciones. Colombia muestra un ascenso en el número de publicaciones en comparación con otros países Latinoamericanos. En los últimos 10 años analizados, las referencias acerca de TCMH, en comparación al total de publicaciones sobre hematología representó un 16.35\%. En este análisis se utilizó el buscador Fabumed, sin embargo, se presentaron limitaciones en la búsqueda debido a que los artículos se centran en los que se publican en inglés y en revistas internacionales. A pesar de esta limitación, este estudio es útil para los investigadores de áreas como hematología y oncología, dado que muestra un panorama general de la investigación en torno a este tema.

\section{Conclusiones}

Esta es la primera revisión bibliométrica realizada en torno a TCMH. En este trabajo se evidencia un creciente interés en el campo de la hematología y las células madre hematopoyéticas en los últimos 20 años. Los países desarrollados son los que presentan mayor volumen de publicaciones, siendo necesario incrementar la investigación en países Latinoamericanos como Colombia que permitan conocer objetivamente la situación actual de TCMH a nivel nacional y sus avances.

\section{Conflicto de Intereses}

\section{Los autores declaran no tener conflictos de interés}

\section{Agradecimientos}

Al semillero de Hematología y trasplantes, Universidad Autónoma de Bucaramanga por hacer este estudio posible.

\section{Referencias}

1. Davila M, Guzmán R, Macareno H, Piñeres D, Dereck D Caballero C. Bibliometría: conceptos y utilidades para el estudio médico y la formación profesional. Salud Uninorte. 2009; 25(2):319-330.

2. Moreno ME, Rosselli DA. Análisis bibliométrico de temas económicos en oncología. MedUNAB. 2012; 14(3):160-166. Disponible en: http:// 132.248.9.34/hevila/Medunab/2011-12/vol14/no3/3.pdf

3. Li D, Wang L, Zhu H, Dou L, Liu D, Fu L, et al. Efficacy of Allogeneic Hematopoietic Stem Cell Transplantation in Intermediate-Risk Acute Myeloid Leukemia Adult Patients in First Complete Remission: A Meta-Analysis of Prospective Studies. PLoS One. 2015; $10(7)$ : e 0132620 . D is pon ible e n : https://doi.org/10.1371/journal.pone.0132620

4. Bladé J, Samson D, Reece D, Apperley J, Björkstrand, Gahrton G, et al. Criteria for evaluating disease response and progression in patients with multiple myeloma treated by high-dose therapy and haemopoietic stem cell transplantation. British Journal of Haematology. 1998; 102(5):1115-1123. Disponible en: https://doi.org/10.1046/j.1365-2141.1998.00930.x

5. Wang X, Li Y, Yan X. Efficacy and Safety of Novel AgentBased Therapies for Multiple Myeloma:AMeta-Analysis. BioMed Research International. [Internet]. 2016. [Citado en abril 20 del 2016]. Disponible en: https://www. hindawi.com/journals/bmri/2016/6848902/cta/

6. Li D, Wang L, Zhu H, Dou L, Liu D, Fu L, et al. Efficacy of Allogeneic Hematopoietic Stem Cell Transplantation in Intermediate-Risk Acute Myeloid Leukemia Adult Patients in First Complete Remission: A Meta-Analysis of Prospective Studies. PLoS One. 2015; 10(7):e0132620. Disponible en: https://doi.org/ 10.1371/journal.pone.0132620

7. Chaudhri NA, Aljurf M, Almohareb FI, Alzahrani HA, Bashir Q, Savani B, et al. Establishing an autologous versus allogeneic hematopoietic cell transplant program in nations with emerging economies. Hematol Oncol Stem Cell Ther. 2017; 10(4):173-177. Disponible en: https://doi.org/10.1016/j.hemonc.2017.05.016

8. Jaimovich $G$, Martinez J, Baldomero $H$, Rivas $M$, Hanesman I, Bouzas L, et al. Latin America: the next region for haematopoietic transplant progress. Bone Marrow Transplantation.2017; 52(5):671-677. Disponible en: https://doi.org/10.1038/bmt.2016.361

9. Instituto Nacional de Salud. Instituto Nacional de Salud respalda la tradición científica y técnica de trasplantes de médula ósea en Colombia. [Internet]. 2016. [Citado $a b r i l \quad 2002016$ ]. D is pon i ble e $n$ : http://www.ins.gov.co/Noticias/Paginas/el-institutonacional-de-salud-respalda-la-tradicion-cientifica-ytecnica-de-trasplantes-de-medula-osea-en-colombia.aspx\#.WEqhcLLhDIV

10. Clínica FOSCAL. Fundación Oftalmológica de Santander Clínica Carlos Ardila Lulle. [Internet]. 2015. [citado abril 13 de 2017]. Disponible en: http://www.foscal.com.co.

11. Sossa C, Peña A, Pérez $C$, Ochoa $M$, Meléndez $H$, Salazar L, et al . Clinical utility of the hematopoietic precursor cells (HPC) count compared to the CD+34 cell count in peripheral blood for prediction of apheresis performance:AB15. Nature. 2016; 51:569-569.

12. Centro de Excelencia en Hemofilias. Social networking. [Internet]. 2016. [Citado abril 13 de 2017]. Disponible en: http://ceht.fundacionisa.org/fb 
13. MEDLINE. Resources Guide. [Internet]. 2006. [citado junio 28 2016]. Disponible en: https://www.nlm.nih.gov/ bsd/pmresources.html

14. Harzing A, Adams D. Publish or Perish: realising Google Scholar's potential to democratise citation analysis. [Internet]. 2016. [citado junio 28 2016]. Disponible en: https://harzing.com/download/gsday madrid.pdf

15. University of Maryland. Bibliometrics and Altmetrics: Measuring the impacto f Knowledge. [Internet]. 2017. [Citado junio 28 2016]. Disponible en: http://lib.guides.umd.edu/bibliometrics/SNIP

16. Leiden University. Centre for Science and Technology Studies. [Internet]. 2016. [Citado julio 01 2016]. Disponible en: https://www.cwts.nl

17. Tarazona N. Stem cell transplantation AND 1970:2015 [dp]. [Internet]. 2016. [citado junio 28 2016]. Disponible en: http://ceht.fundacionisa.org/fb

18. Zhang L, Ye X, Sun Y, Deng A, Qian B. Hematology research output from Chinese authors and other countries: a 10-year survey of the literature. Journal of Hematology \& Oncology. 2015;8(1):1-3. Disponible en: https://doi.org/10.1186/s13045-014-0103-3

19. Lin C, Ho Y. A Bibliometric Analysis of Publications on Pluripotent Stem Cell Research. Cell J. 2015; 17(1):5970. Disponible en: https://doi.org/ 10.22074/cellj. 2015.512

20. Glynn R, Chin J, Kerin M, Sweeney K. Representation of Cancer in the Medical Literature -ABibliometricAnalysis. PLoS ONe. 2010; 5(11):e13902. Disponible en: https://doi.org/10.1371/journal.pone.0013902
21. Cornelissen J, Versluis J, Passweg J, van Putten W Manz M, Maertens J, et al. Comparative therapeutic value of post-remission approaches in patients with acute myeloid leukemia aged 40-60 years. Leukemia. 2014; 29(5):1041-1050. Disponible en: https://doi.org/ 10.1038/leu.2014.332

22. Shah N, Callander N, Ganguly S, Gul Z, Hamadani M, Costa L, et al. Hematopoietic Stem Cell Transplantation for Multiple Myeloma: Guidelines from the American Society for Blood and Marrow Transplantation. Biol Blood Marrow Transplant. 2015; 21(7):1155-1166. Disponible en: https://doi.org/10.1016/j.bbmt.2015.03.002

23. Perales M, Ceberio I, Armand P, Burns L, Chen R, Cole $P$, et al. Role of Cytotoxic Therapy with Hematopoietic Cell Transplantation in the Treatment of Hodgkin Lymphoma: Guidelines from the American Society for Blood and Marrow Transplantation. Biol Blood Marrow Transplant. 2015; 21(6):971-983. Disponible en: https://doi.org/10.1016/j.bbmt.2015.02.022

24. Peffault de Latour R, Peters C, Gibson B, Strahm B, Lankester A, de Heredia C, et al. Recommendations on hematopoietic stem cell transplantation for inherited bone marrow failure syndromes. Bone Marrow Transplant. 2015; 50(9):1168-1172. Disponible en: https://doi.org/10.1038/bmt.2015.117

25. Acevedo A, Gómez A, Becerra H, Ríos A, Zambrano P, Obando $\mathrm{E}$, et al. Distribution and trends of hematology and oncology research in Latin America: A decade of uncertainty. Cancer. 2013; 120(8):1237-1245. Disponible en: https://doi.org/10.1002/cncr.28539 